B. PAPERS From Which Illustrations and Experiments have BEEN taken

GrILlNER, S. (1969). Supraspinal and segment control of static and dynamic $\gamma$ motoneurones in the cat. Acta physiol. scand. Suppl. 327, p. I6.

GRILLNER, S. \& LUND, S. (I968). The origin of a descending pathway with monosynaptic action on flexor motoneurones. Acta physiol. scand., 74, 274-284.

HolmQvist, B. \& LUNDBERG, A. (1959). On the organization of the supraspinal inhibitory control of interneurons of various spinal reflex arcs. Arch. ital. Biol., 97, 340-356.

HolmQvist, B. \& LUNDBERG, A. (I96I). Differential supraspinal control of synaptic actions evoked by volleys in the flexion afferents in alpha motoneurones. Acta physiol. scand., 54. Suppl. I86.

Hultborn, H., JANKOWSKa, E. \& Lindström, S. (1968). Recurrent inhibition from motor axon collaterals in interneurones monosynaptically activated from Ia afferents. Brain Research, 9, 367-369.

Lund, S. \& Pompeiano, O. (I968). Monosynaptic excitation of alpha motoneurones from supraspinal structures in the cat. Acta physiol. scand., 73, I-2I.

LUNDBERG, A. (1964). Supraspinal control of transmission in reflex paths to motoneurones and primary afferents. Progr. Brian Res., 12, 197-219.

\title{
SPINAL SHOCK AND REFLEX BEHAVIOUR IN MAN
}

By Professor Sir Ludwig Guttmann, C.B.E., M.D., F.R.C.P., F.R.C.S.

SINCE Marshall Hall (I84I) introduced the term 'spinal shock' for the state of in- or hypoexcitability of the isolated cord which exists immediately and in the early stages following transection of the spinal cord, this phenomenon has repeatedly been the subject of clinical and physiological research and discussion. While the majority of modern investigators came to the conclusion that spinal shock represents a dysbalance of the function of the internuncial neurons and not of the motoneurons, the intrinsic mechanism of this phenomenon and its variations amongst the various species in the evolutionary scale are still not wholly understood. One of the reasons for this is the fact that experimental workers in this field adopted different technical procedures and modes of investigations including different types of anaesthesia. This is in particular the case when the functions of the spinal cord have been studied in preparations of animals of higher types in the evolutionary scale. Koley's and Muckerjee's (1964) comments on the techniques used are as follows:

(I) Sherrington's preparations were not a spinal preparation, but a decapitate preparation.

(2) The technique of pithing the cord used by Goltz (I864) is suitable only in small animals such as frogs and guinea-pigs.

(3) Treat's technique (I94I) used in cats by blind puncture and cauterisation, avoiding traumatic effects of laminectomy, has the uncertainty of complete separation of the cord.

(4) McDowall's technique, adopted more or less by Downman, McSwiney and Muckerjee himself is a preparation which converts the preparation into 'decerebrate with cordotomy'. Artificial respiration was always required to maintain the life of the animal.

Nevertheless, the modern concept of spinal shock is based on the work of Sherrington and his school, which suggests that the transient reflex depression in 
the segments below the spinal cord transection is the result of the sudden withdrawal of a predominantly facilitating or excitatory influence of supraspinal structures, resulting in a disruption of transmission at the synapse and thus rendering the process of conduction impossible or difficult. In recent years, thanks to the work of Eccles and his colleagues, much of the research is concerned with the mechanism of synaptic excitation and inhibition and, moreover, the importance of the peripheral organs in the muscle system has been more and more recognised in the process of transmission. It has been concluded that a primary factor in the tendineous areflexia in spinal shock is the reduced discharge of spindle receptors, produced by relaxation of intrafusal muscle fibres through the acute deficit of the fusimotor control from the gamma-motor neurons.

I propose to discuss in this survey certain factors influencing reflex behaviour of the skeletal muscles during and after the stage of spinal shock following spinal cord transection, with special reference to the spinal man. Time does not allow to discuss in detail the effects of spinal cord transection during spinal shock on the visceral mechanisms and homeostatic complexes such as temperature regulation, and I must refer to previous publications (Guttmann, 1946, I953, I954, I967, I969; Guttmann \& Witteridge, I947).

I. Latent Period between Time of Cord Transection and Spinal Shock. There is the question whether the sudden withdrawal of the innervatory influence from supraspinal centres as the result of cord transection disrupts the transmission at the synapse in the segments caudal to the lesion immediately, or whether the ganglion cells at the synapse still retain their charge of energy and excitability for a short period and are thus capable of maintaining for a while the process of conduction. I have found the ankle jerks, plantar response, anal sphincter and bulbo-cavernosus reflex to be still present immediately after cord transection and they may disappear only after a certain latent period. It is well known that immediately after decapitation in man, the knee jerks are still elicitable for several minutes. In this connexion it may also be remembered that Collier (1916, 1917) succeeded in the first days following cord transection in eliciting the initially abolished knee and ankle jerks following faradisation of the quadriceps for 5 to I 5 minutes, and Lewandowski and Neuhoff succeeded by faradisation of the paralysed leg to elicit the abolished ankle jerk and Babinski reflex. These observations of clinical neurologists are today of particular interest in the light of recent physiological research on spinal shock, as they indicate that the sudden withdrawal of the excitatory influence of supraspinal centres on the transmitting synapses in the stage of spinal shock can be temporarily replaced by strong peripheral afferent impulses. Conversely, Foerster (I9II) proved the importance of the afferent system on the reflex activity of the spinal cord by dividing the posterior roots resulting in distinct though, according to number of divided roots, variable degree of reflex depression. All these observations of the old school of clinical neurologists have been invaluable in furthering our knowledge in the neurophysiology of the spinal man. There is no doubt that neurological examinations at frequent intervals by the same examiner during the immediate and early stages following complete as well as incomplete traumatic lesions of the spinal cord are of utmost importance in determining intensity, duration and direction of spinal shock as well as evaluating the intricacy of reflex return in the spinal man. Therefore the need of accurate records cannot be overstressed, the more so as the modern student can now approach 
this subject with more sophisticated methods of investigation than the investigator of the past.

2. Intensity and Duration of Spinal Shock. It is now generally agreed that intensity and duration of spinal shock increase commensurate with the vertebrate scale, especially in the primate series. A comparison of different species reveals a striking parallel between the degree of development of suprasegmental structures and their descending tracts on the one hand and the intensity and duration of the spinal shock resulting from the cord transection on the other. Sherrington found it impossible to elicit the knee jerks for about a month in the case of a monkey, whilst in a rabbit its absence lasted only io to 15 minutes. In lower species reflex activity may even occur without delay after severance of the cord. Fulton and McCouch (1937) found that in the Erythrocebus group of monkeys all reflex depression in the macaque, baboon and especially the chimpanzee may be almost as great as or even greater than in man.

The duration of spinal cord depression in man varies considerably, and reflex activity of skeletal muscles may appear within a period from three or four days (this occurs in particular in young individuals) and up to six weeks after injury. The physiological derangement in the isolated cord also affects the automatic mechanisms, and the onset of automaticity of bowels and in particular bladder may be considerably delayed, as may be the dysbalance of temperature regulation, especially in transections of the cervical cord.

The reflex depression is, as a rule, more severe and lasts longer in the segments of the isolated cord situated more proximal to the transection than in the distal segments. The reflex patterns occurring in the following case following cord transection may be quoted as a typical case.

A soldier aged 23 sustained a gunshot injury on $\mathbf{2 . 7 . 4 4}$ of the Ioth thoracic vertebra resulting in a complete transverse spinal syndrome below $\mathrm{T} 9$ with flaccid paraplegia. The medical notes stated that he was very shocked but he recovered following blood transfusions. One day later a suprapubic cystostomy was performed. Twelve days after injury he was examined by Dr. George Riddoch, no doubt the most experienced neurologist on spinal injuries in the war. The patient then still showed a complete flaccidity of both lower limbs and areflexia with the exception of the ankle jerks, which showed just a flicker. There was a complete loss of control of bladder and bowels. Eighteen days after injury he was admitted to Stoke Mandeville Spinal Centre. There was still a complete transverse spinal syndrome below $\mathrm{T}_{9}$ and Table I demonstrates the return of reflex function in this case.

In this case the recovery of reflex function from spinal shock occurred within six weeks after accident and it may be noted that although the ankle jerks returned earlier the intensity of reflex response became more marked in the knee jerks once these returned. Moreover, while at first the flexion synergy of the lower limbs was predominant it gradually diminished and was replaced by the prevalent extension synergy.

Another example is a young soldier, aged I9, who sustained a complete tetraplegia below $\mathrm{C}_{7}$ as the result of a fracture dislocation of $\mathrm{C}^{6}$ following diving into shallow water. $\mathrm{He}$ was seen on the day of injury on $\mathbf{1 3 . 8 . 4 4}$ by a neurologist who reported complete paralysis below $\mathrm{C} 8$ of flaccid type with areflexia including the triceps jerk. There was, however, a plantar flexion response to plantar stimulation on both sides. There was also priapism. On admission to Stoke Mandeville one day later, he had a bilateral Horner's 
TABLE I

\begin{tabular}{|c|c|c|c|c|c|c|c|c|c|c|c|c|c|c|}
\hline & & & & & \multicolumn{2}{|c|}{20.7 .44} & \multicolumn{2}{|c|}{ I2.8.44 } & \multicolumn{2}{|c|}{28.8 .44} & \multicolumn{2}{|c|}{20.1 I. 44} & \multicolumn{2}{|c|}{$\mathrm{I} 4 \cdot 5 \cdot 45$} \\
\hline & & & & & $\mathbf{R}$ & $\mathbf{L}$ & $\mathbf{R}$ & $\mathbf{L}$ & $\mathbf{R}$ & L & $\mathbf{R}$ & L & $\mathbf{R}$ & L \\
\hline \multirow[t]{2}{*}{ Abdominals } & . & . & . & . & + & + & + & + & + & + & + & + & ++ & ++ \\
\hline & & & & & + & + & + & + & + & + & + & + & + & + \\
\hline Cremasterics & . & . & . & . & - & $\overline{-}$ & $\begin{array}{l}- \\
-\end{array}$ & $\begin{array}{l}- \\
-\end{array}$ & - & $\begin{array}{l}- \\
-\end{array}$ & $\begin{array}{l}- \\
-\end{array}$ & - & $\overline{-}$ & $\overline{-}$ \\
\hline K.Js. • & . & . & . & . & - & - & + & + & + & + & ++ & ++ & ++ & $\stackrel{+}{+}$ \\
\hline A.Js. & . & . & . & . & $((+))$ & $((+))$ & $(+)$ & $(+)$ & $(+)$ & $(+)$ & ++ & ++ & & $\begin{array}{c}\text { (clonus) } \\
++ \\
\text { (clonus) }\end{array}$ \\
\hline Plantars . & . & . & . & . & $\downarrow$ & $\downarrow$ & & $\uparrow$ & & $\uparrow$ & $\uparrow$ & $\uparrow$ & $\uparrow$ & $\uparrow$ \\
\hline Withdrawal & . & . & . & . & - & - & $(+)$ & $(+)$ & $\stackrel{+}{+}$ & $\stackrel{+}{+}$ & ++ & ion) + & 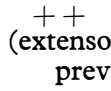 & $\begin{array}{c}++ \\
\text { synergy } \\
\text { alent) }\end{array}$ \\
\hline
\end{tabular}

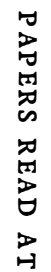

TABle II

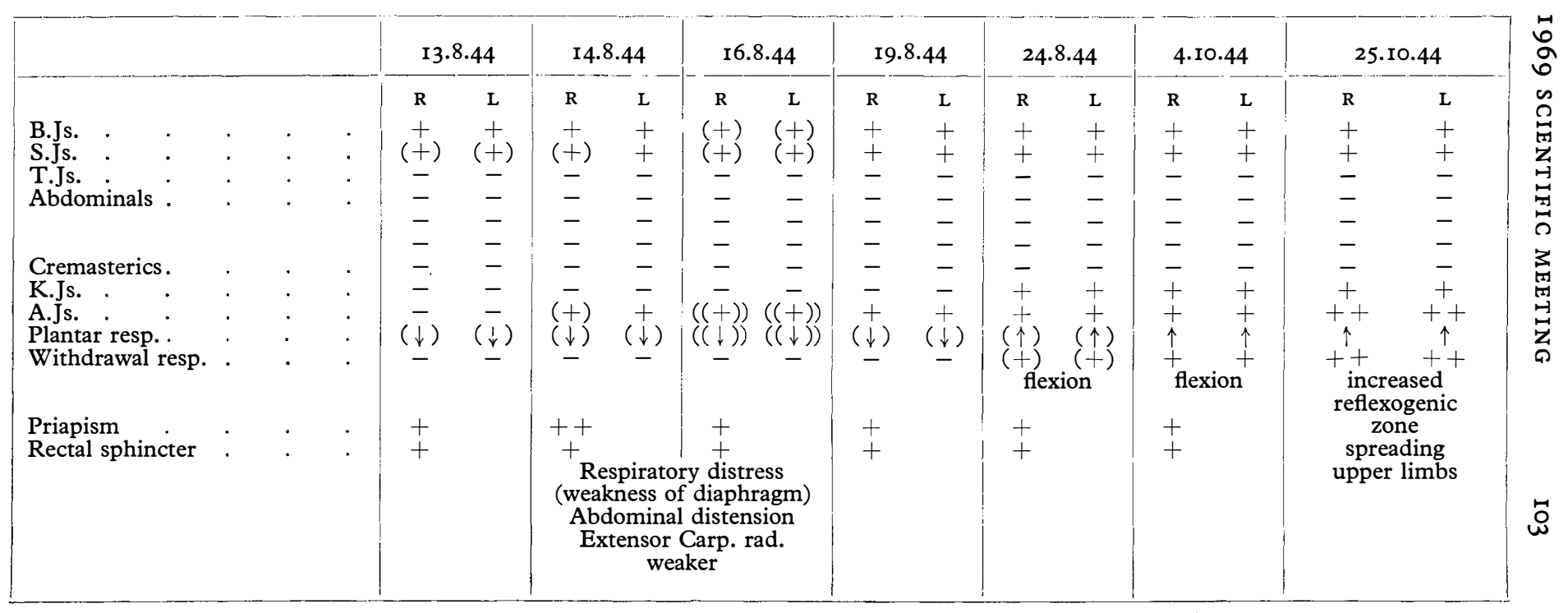


TABLE III

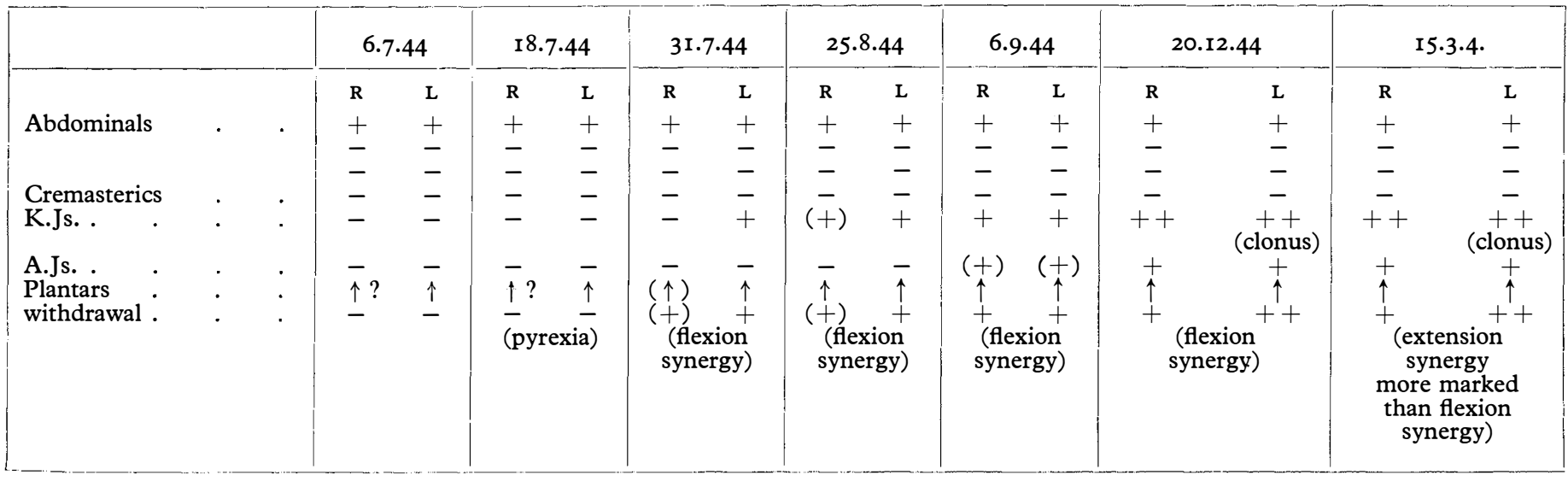

\section{Table IV}

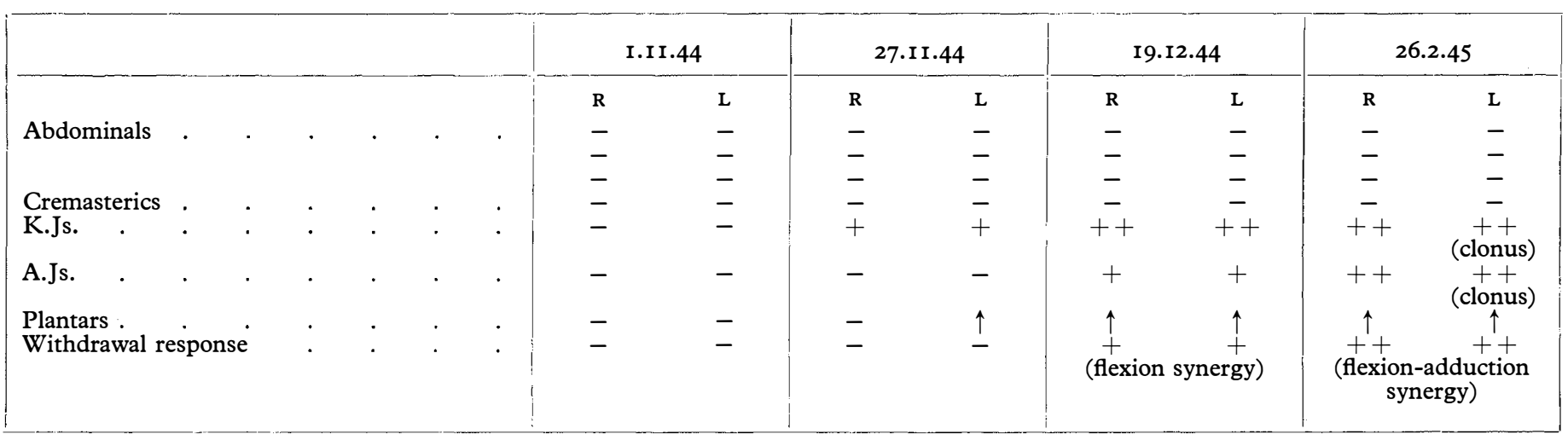


syndrome marked vasodilation in face and neck with obstruction of the naso-pharyngeal passages, paralysis of both triceps and of all finger and hand muscles with the exception of the extensors of the wrist and the radial portion of the extensor digitorum on the left. There was complete sensory loss below C8 but also marked sensory impairment in $\mathrm{C}_{7}$. Bladder and bowel control was lost and there was a total collapse of the right lung. The pattern of reflex return in this case is shown in Table II which also shows a gradual reflex recovery in the upwards direction. At the end of October 1944 a marked increase of the reflexogenic zone along the whole paralysed area of the body was noted. Plantar stimulation on either side not only set up marked flexion synergy of the ipsilateral paralysed leg but also resulted in contraction of the ipsilateral trunk muscles and marked response of the paralysed extensors of all fingers and thumb on the same side. This extensive reflex response of the fingers and thumb on stroking the sole of the left foot could be elicited bilaterally but only ipsilaterally on stroking the right sole. In due course this exaggerated reflex response gradually diminished in intensity but was still elicitable. Moreover, the profound flexion synergy of the lower limbs gradually decreased and in the middle of 1946 was replaced by a prevalent extensor synergy.

In contrast to this group of patients with early return of the ankle jerks, there are other complete transverse lesions where the return of the tendon reflexes nearer to the transection such as the knee jerk, may precede that of the ankle jerk as shown in the following example.

A soldier, aged 20 , sustained a complete transverse lesion below T8 with a right haemopneumothorax as a result of a gunshot injury on 25.6.44. One day later a suprapubic cystostomy was performed. On admission to Stoke Mandeville II days after injury he showed flaccid paralysis of both lower limbs with a complete sensory loss below T8 and loss of control of bladder and bowels. The pattern of reflex return is shown in Table III. While in this case the extensor response of the big toe to plantar stimulation appeared much earlier than either knee or ankle jerks, the knee jerks returned before the ankle jerks and it may be noted that there was not only a definite delay in the return of the right ankle jerk but the intensity of the withdrawal response was also less marked on the right side, indicating a difference in the intensity of the spinal shock between the two halves of the spinal cord below the level of the lesion.

A further case in this group is a soldier aged I9, who sustained a gunshot injury to the 7 th cervical vertebra resulting in a complete transverse lesion below $\mathrm{Tr} / 2$. He was operated upon one day later and the spinal cord was found almost completely severed by a foreign body which was removed. A suprapubic cystostomy was performed on the same day. On admission to Stoke Mandeville three days later there was a complete flaccid paraplegia below TI with paralysis of the abductor pollicis longus and brevis and slight weakness of the long finger flexors on the right side. The paralysis of the lower limbs and trunk was flaccid and there was a complete sensory loss below $\mathrm{T}_{\mathrm{I}}$ on the right and $\mathrm{T}_{2}$ on the left with an incomplete Horner's syndrome on the right. Bladder and bowels paralysed. The pattern of reflex return in the lower limbs and abdominals is shown in Table IV.

From all the tables it has been seen that the cremaster reflex has been absent throughout and remained so. This observation, which I confirmed again and again, is not in accordance to other authors who claim that the cremaster reflex returns as a rule early.

3. Headward Direction of Functional Depression. From experimental studies on cord transection in animals it was for many years accepted that the transient depression of the excitability of the cord in the stage of spinal shock 
manifests itself in caudal direction only. Sherrington mentioned as an example of the absence of headwards spread of depression due to spinal shock the fact that, in spinal animals after transection of the 5 th cervical segment, the respiratory activity of the phrenic motor cells is hardly affected and in transection behind the brachial enlargement he found the reaction of the four limbs little if at all disturbed. However, this concept was not confirmed by Ruch and Watts (1934), who described distinct changes in reflex activity following post-brachial transection or cold block of the spinal cord. Earlier, Monakow (I9I4), who introduced the term 'diaschisis' (meaning dissolution of neural function), postulated that diaschisis is operative not only in the downward direction but also upwards. From my personal experience in traumatic complete lesions in man an upward spread of transient depression of cord function in the initial stages of spinal shock is by no means unusual. For instance, the transient impairment of finger movement and loss of reflex of the forearm may occur in upper thoracic lesions as low as $\mathrm{T}_{4}$. However, this transient impairment may disappear within a few hours or few days after injury.

\section{FACTORS INFLUENCING REFLEX SYNERGIES}

It is generally accepted that the first reflex synergy appearing following spinal shock is the flexion synergy of the paralysed legs. The earliest co-ordinated movement of the lower limbs in the spinal man is the ipsilateral flexor reflex, and flexor responses dominate the reflex activity of the isolated cord in the early stages following cord transection. Riddoch (1917), studying the activities of the flexor and extensor reflex arcs of the paralysed lower limbs, advanced the thesis that it is frequently possible to say whether conduction of the spinal cord has been completely destroyed or not. This has led to the conception that paraplegia-in-flexion is pathognomonic of complete transection of the cord while paraplegia-in-extension is pathognomonic of incomplete lesions. Moreover, Fulton, Liddell and Rioch's animal experiments (1930) indicated that the extensor hypertonus depends on the transmission of postural reflexes along intact vestibulo-spinal and probably also ventro-reticulo-spinal pathways to the cord centres below the level of the lesion and only destruction of these tracts results in a preponderance of the flexor reflexes or paraplegia-in-flexion. However, Sherrington found a variability in the order of recovery of the various spinal reflexes from spinal shock in the dog, following complete transection of the cord, and in some individuals a preponderence of extensor rigidity was evident: 'The limbs are kept extended at knee and ankle to a degree that it is difficult to break through by the inhibition accompanying elicitation of the flexion reflex stimulation of the foot.' Sherrington's explanation is that 'some incidental circumstances determining the preponderance of some passive attitude of the limb during the early days succeeding the lesion may, by its influence on the interaction of the recovering spinal arcs, impress an unwanted reflex habit about the limb'. The great number of traumatic paraplegic survivors from World War II prompted me to study this important problem in spinal man (1946, 1952, 1953, 1969). From all my observations there can be no doubt about the great influence which the position of the paralyzed limbs during the early stages of paraplegia has on the development of the pattern of reflex synergies in later stages, in both complete and incomplete lesions of the spinal cord. It was found that in those paraplegics with complete cord transection who did not develop flexion contractures during the early stages, whose general condition remained 
satisfactory and in particular who were free from sepsis, the initially predominant flexion synergy gradually diminished in due course and the extensor reflex synergy became predominant. In this connexion it may be remembered that Riddoch himself had already found that, in later stages of heightened reflex activity of complete lesions the difference in the tone of the extensor and flexor groups (the latter being predominant) becomes less marked. Foerster (1936) reported two cases of transection of the cord of over one year's duration, with preponderance of extension reflex synergy. In one of these cases the extensor reflex of the legs could be elicited in both legs by stimuli applied to the ano-genital region. Further proof of the great variability in the reflex activity was given by Elkins and Wegner (1946) Scarff and Poole (1946), Dick (1949) and Kuhn and Macht (1948). The latter authors described 28 patients with complete transection at levels between $\mathrm{T} 2$ and Ti2 which they followed up for two or more years as follows:

Flexor spasms, 2.

Extensor spasms predominant over flexor spasms, 19.

Pure extensor spasms, 0

Flaccid, 5 .

Amongst the factors influencing the pattern of spasticity I found attitudes and posture in paraplegics (whether the lesion be complete or incomplete) already most important in the early stages following injury. In particular, prolonged fixation of the paralysed limbs in adduction and semi-flexion as produced by placing a pillow under the knees, invariably promotes predominant flexor synergy and consequently paraplegia-in-flexion (Guttmann, 1946). The explanation is that the constant approximation of the insertion points of the flexors of hips and knees in such cases causes facilitation (Bahnung) of their stretch reflex and at the same time the constant over-stretching of their antagonists, the extensors of hips and knees result in a weakening of the stretch reflex of the latter. Conversely, factors which have proved effectual in facilitating extensor activity are:

I. Placing the paralysed limbs during spinal shock in abduction and extension at hips and knees while the patient lies in supine position.

2. Placing the patient in prone position, which, particularly in high thoracic and cervical lesions, like in babies whose pyramidal tracts are not yet developed, promotes the extension reflex of the body.

3. Early passive movements of the paralyzed limbs.

4. Restoration of the upright position of the paraplegics and tetraplegics-in particular standing in parallel bars.

It has already been pointed out that prolonged overstretching of the skeletal muscles by faulty positioning of the paralysed limb causing structural damage of the muscle and resulting in unrestrained action of its antagonist represents an important factor in determining the reflex pattern of the paralyzed limb. Another common cause of structural damage of a muscle and its peripheral nerve supply is pressure produced by plaster or splint. In this connexion, the constant pressure against the capitulum fibulae causing damage to the popliteal nerve and thus resulting in paresis or paralysis of the tibialis anterior and the dorsi-flexors of the toes is one of the frequent causes of the predominance of the plantar flexors of the toes and foot. 


\section{VARIETIES OF REFLEX ACTIVITY FOLLOWING CESSATION OF SPINAL SHOCK}

It is, of course, beyond the scope of this paper to describe in detail all the varieties of reflex patterns found in the paralysed limbs following complete lesions of the cord once the spinal shock has ceased. However, at least three groups may be examined, in which certain muscles or muscle groups are dominant in the reflex synergy.

I. Preponderance of the Extensor Hallucis Longus and the Tibialis Anterior. The contraction of the extensor hallucis longus on plantar stimulation represents one of the original components of both extensor and flexor synergies. It is indeed one of the very early signs of reflex activity of the isolated cord. Although this reflex was first described by E. Remark (I893), it was Babinsky (I896) who realised the clinical significance of the phénomène du gros orteil which is generally accepted as Babinsky's sign. It is well known that the distribution of this reflex zone and the intensity of its motor response varies. Sometimes the extensor hallucis longus may show a profound preponderance over any other muscles of the lower limbs and in some patients the contraction of this muscle may be permanent. In one of my patients with a complete transverse lesion below $\mathrm{T}_{4}$ in which this muscle contraction was continuously present a subluxation of the terminal phalanx of the toes was the final result (Guttmann, I953).

In the same group of reflex response belongs the tibialis anterior. The reflex contraction of this muscle either in combination with the extensor hallucis longus or isolated may become so continuous that finally a contracture of the foot in dorsiflexion and supination occurs.

2. Preponderance of Plantarflexors of Feet and Toes. In several patients with complete lesions resulting in marked spasticity of the paralysed legs a profound preponderence of the plantarflexors of the feet and toes was found. This may occur in one leg only though it was repeatedly seen bilaterally. This can occur either by keeping the feet and toes in plantarflexion during the stage of spinal shock and not at the right angle, or as a result of a pressure lesion of the popliteal nerve at the level of the head of the fibula through faulty position and care in the early stages following transection of the cord. This peripheral nerve lesion can be diagnosed by the absence of any reflex response to cutaneous stimuli within the area of cutaneous distribution of the external popliteal nerve-for instance by pricking or stroking with a pin. Reflex response to nociceptive stimuli are obtained only at the border of the cutaneous distribution of this nerve. Moreover, electrical examination of the muscles in question and in electromyogram will reveal complete or incomplete R.D. of the muscles supplied by the external popliteal nerve.

3. Synchronous Rhythmic Contractions. Rhythmic, alternating flexion and extension contractions of the paralysed lower limbs have been previously described by Riddoch (1917) and Foerster (1936), and special mention may be made of the coitus reflex described by Riddoch as an example of rhythmic alternating flexion and extension synergies of the hips.

Rhythmic contraction may also occur synchronously. One of my patients, a 
young soldier with a complete lesion below $\mathrm{T}_{3}$ whose paraplegia since his injury in 1944 gradually developed from a flexion into an extension synergy showed interesting rhythmic synchronous contractions occurring only in the tibialis posterior on both sides. These rhythmic contractions occurred spontaneously at rest in bed, but the intensity and rate could be increased by various stimuli, including change of posture. Rhythmic contractions can also occur, although infrequently, in the extensor group of the trunk erectors, and can become very troublesome to the patient and make his life miserable. In one of my tetraplegics these rhythmic contractions of the trunk erectors could be eliminated following intra-thecal alcohol block.

\section{SUMMARY}

This paper deals with the effects of spinal cord transection on the reflex function of the isolated cord in the spinal man in relationship to these effects following cord transection in animals.

Details are presented of latent period, intensity and duration of the reflex depression of skeletal muscles during the period of spinal shock caudal and cephalad of the cord transection.

Factors influencing the patterns of reflex recovery are described and special attention is drawn to the effect of posture during spinal shock on the development of flexion and extension synergies.

Varieties of reflex pattern due to preponderance of individual muscles occurring after cessation of spinal shock are discussed and special mention is made of the phenomenon of synchronous rhythmic muscle contractions.

\section{REFERENCES}

BABINSKI, J. (I896). Compt. rend. Soc. biol., 3, 207.

Collier, J. (I9I6). Lancet, I, 7I I.

DICK, T. S. (I949). Rehabilitation in Chronic Paraplegia, M.D. Thesis Manchester Univ. Elkins, C. W. \& WegneR, W. R. (I946). Ann. Surg. II3, 5 I6.

FoERSTER, O. (1936). Symptomatologie der Erkrankungen des Rückenmarks, Vol. 5, 206. Berlin: Springer.

Fulton, J. F., LidDELl, E. G. T., Rioch, D. McK. (1930). Brain, 53, 31 I.

Fulton, J. F. \& McCouch, G. P. (1937). F. Nerv. and Ment. Dis. 86, I25.

GutTManN, L. (1946). Brit. F. Phys. Med., 9, I62.

Guttman, L. (1952). F. Nerv. and Ment. Dis., 116, 957.

GuttmanN, L. (I953). The Treatment and Rehabilitation of Patients with Injuries of the Spinal Cord. Monograph in Brit. Med. History of World War II., Vol. Surgery, 43I444.

Guttmann, L. (1954). Visceral Activity and Peripheral Circulation, p. 192. London: Churchill.

GutTMANN, L. (I968). The Re-orientation of posture and locomotion in spinal man: Kovacs-Mem. Lecture, Proc. Roy. Soc., I, 47.

Guttmann, L. (1969). Handbook of Clinical Neurology, Vol. 2, 178-216. Edit. P. J. Vinken and G. W. Bruyn. Amsterdam: North-Holland C.

GuttmanN, L. \& WhitTeridge (1947). Brain, 70, 36I.

Hall, M. (I94I). On the Diseases and Derangements of the Nervous System, p. 256. London: Baillière.

Koley, B. N. \& Mukherjee, S. R. (1964). F. Exp. Med. Sci., 8, I4.

Kunn, R. A. \& MACHT, M. B. (I948). Arch. Neurol. \& Psychiatr., 59, 745.

MonaKow, C. vON (I9I4). Lokalisation im Grosskirn, p. 257. Weisbaden: Bergmann.

Remak, E. (1893). Neurol. Centralbl., I2, 506.

RIDDOCH, G. (I9I7). Brain, 40, 264. 
Ruch, T. C. \& Watts, J. W. (1933). Am. F. Physiol., I05, 86.

SCARFF, J. E. \& PoOL, J. L. (1946). F. Neurosurg., 3, 285.

Sherrington, C. S. (I947). The Integrative Action of the Nervous System. Second Ed. New Haven: Vale Univ. Press.

\section{Discussion}

F. W. ME INECKE (Germany). May I make one suggestion? There is a big confusion, especially amongst the accident surgeons, between the two terms, spinal shock and traumatic shock, and I think it would be worth while to give a definition of the term spinal shock and to publish it in the paper so that we can tell the people what we mean.

Sir Ludwig Guttmann (G.B.). I am glad about this question. The spinal shock must not be confused with the general traumatic shock. In spite of some resemblances, such as fall of blood pressure in cord lesions above $\mathrm{Th}_{5}$, there are fundamental differences. The reflex depression in spinal shock in the isolated cord area is just as profound in distal thoracic cord transection where the blood pressure is not reduced. The disturbed blood circulation due to traumatic shock can be restored but this has no, or only insignificant, influence on the reflex depression due to spinal shock. Moreover, reflex depression of the isolated cord is equally profound whether the anterior spinal artery is severed or not. Therefore, spinal shock represents an independent phenomenon from the disturbed blood circulation due to traumatic shock.

H. L. Frankel (G.B.). I should like to thank the two main speakers, whose efforts I greatly enjoyed this morning. However, I would like to ask them (presumably they do not know or they would have told us by now) the mechanism of spinal shock. Perhaps they could make one or two intelligent guesses, just to keep us further interested. I would, as a clinician, like to know what are the mechanisms or substances. I would like to give the antidotes from the start, because I would like to get the sphincters working quicker and I also would like to avoid the alarming vagal overactions we sometimes get. We have heard today mainly about what spinal shock isn't. Would either of the openers like to go further into some of the possible mechanisms that are involved.

Professor Ascoli (Italy). I should be very thankful to Sir Ludwig if he could tell us something about the return of sensibility and of vesical function after spinal shock. It is of practical interest.

P. Dollfus (France). I am called by the Colmar Traumatology Unit to see patients within about $\frac{3}{4}$ to I hour after injury, which is most interesting. Being a pupil of Sir Ludwig's, naturally I examine the patient fully (laughter). I say fully because some neurological examinations in these traumatic lesions are not done. One case has appeared to be very interesting. It was a young man of 18 with a complete lesion below C4. This boy never ceased passing his urine with an automatic bladder. We found urine on his clothes when he was admitted-I was rather surprised by this fact, although it has been described. Afterwards, he always had I00 cc. to I $50 \mathrm{cc}$. residual urine but his bladder remained automatic all the time. Also, furthermore, he had never stopped having an anal reflex. I have found the anal reflex very early, being practically the only reflex present until the others developed.

P. HARRIS (G.B.). I would like, like the others, to congratulate our two speakers. I would like to know about the terms 'spinal concussion' and 'spinal shock'. These terms are terribly important to all of us, because of the obvious physiological and clinical con- 